\title{
Diálogos entre literatura e jornalismo em Angola na passagem do século $X I X$ ao $X X$
}

\author{
Sheila Ribeiro Jacob \\ (Universidade Federal Fluminense)
}

\section{RESUMO}

Neste artigo abordamos o início do jornalismo em Angola, no século XIX, e a sua importância para a divulgação e o incentivo à literatura que começava a ser produzida então. Veremos o diálogo entre ambos os movimentos, tanto no século XIX, com a atuação de Alfredo Troni e Cordeiro da Matta, quanto no século XX, quando romancistas tomaram como inspiração a geração da imprensa do século anterior.

PALAVRAS-CHAVE: Imprensa livre angolana, literatura, século XIX.

\section{ABSTRACT}

In this work we will broach the beginning of the journalism in Angola, in the 19th century, and its importance to the divulgation and incentive to the literature that started to be produced by then. We will see the dialogue between both movements such in the $19^{\text {th }}$ century, with the actuation of Alfredo Troni and Cordeiro da Matta, as in the $20^{\text {th }}$ century, when writers took as inspiration the press generation of the previous century.

KEYWORDS: Angola's Free Press; literature; $19^{\text {th }}$ century 
O século XIX tem importância fundamental no percurso intelectual de Angola, e é interessante voltarmos a ele para entender de que maneira a chegada do prelo ao país serviu para a divulgação e o incentivo à produção literária angolana. O responsável pela publicação do primeiro órgão de imprensa em Angola foi o Governador-Geral Pedro Alexandrino da Cunha, que, logo após assumir o cargo, ordenou a criação de um boletim ligado à administração portuguesa. Em 13 de setembro de 1845, saía, então, o número inaugural do Boletim do Governo-Geral da Província de Angola, que, após algumas mudanças de nome, em 1951 passaria a chamar Boletim Oficial de Angola. Esse veículo, destinado aos intereses coloniais, servia como espaço de publicação das ordens e determinações da metrópole, anúncios comerciais e crônicas de viagens. Por outro lado, o Boletim do Governo também serviu para divulgar as manifestações iniciais de uma literatura angolana que dava, então, seus primeiros passos. Nesse órgão circularam, por exemplo, poemas do luandense José da Silva Maia Ferreira, considerado não apenas o primeiro poeta angolano, mas também o primeiro autor africano de língua portuguesa a publicar um livro. Sua obra, Espontaneidades da Minha Alma, data de 1849 e foi inclusive impressa pelo único prelo que havia então: a Imprensa de Luanda, na qual também era rodado o Boletim do Governo.

Após cerca de 20 anos do início da atividade jornalística em Angola, ocorreu no país um expressivo movimento cultural protagonizado por intelectuais que serviriam de inspiração para os jovens poetas no século seguinte: houve um verdadeiro "surto" da Imprensa Livre angolana, com o lançamento de quase sessenta jornais independentes, nos quais tanto africanos quanto europeus constavam como seus diretores, redatores e colaboradores. Muitos desses periódicos lançaram-se em denúncia das condições de exploração existentes no continente africano e em defesa dos interesses dos oprimidos pelo sistema colonial, além de também servirem como polo divulgador e incentivador da produção literária, tanto em prosa quanto em versos. Foi nesses jornais que apareceram, pela primeira vez, poetas como Lourenço do Carmo Ferreira, Maia Ferreira, Cordeiro da Matta, Arsílio Pompeu do Carpo, João da Cruz Toulson, Álvares Paes, e outros.

O primeiro desses periódicos independentes surgiu em $1856 \mathrm{com}$ o nome de A Aurora. Deste, contudo, pouco se sabe, e por isso costumase dizer que o inaugurador de fato da imprensa livre angolana foi o jornal A Civilização da África Portuguesa, editado pela primeira vez em 6 de dezembro de 1866 por Antonio Urbano Monteiro de Castro e Alfredo Júlio Cortez Mântua, ambos colonos que se dedicaram a tratar de assuntos comerciais referentes a Angola e São Tomé. Também foram divulgados alguns poemas em seu jornal, muitos deles escritos pelo próprio Urbano de Castro, um dos símbolos dos intelectuais do final do século XIX, tendo sido notável advogado, jornalista, prosador e poeta. A Civilização da África Portuguesa, que se afirmava abolicionista e lutou "contra a escravatura em todos os seus números" (OLIVEIRA, 1997, p. 52), durou três anos e serviu de influência aos jornais considerados polêmicos que seriam lançados até a primeira década do século $\mathrm{XX}$, muitos deles com curta duração. Dentre os principais títulos estão O Mercantil de 1870; O Cruzeiro do Sul, de 1873; Jornal de Loanda, de 1878; O Echo de Angola, de 1881; 
A União Áfrico-Portuguesa, de 1882; A Verdade, de 1882; O Futuro de Angola, de 1882; O Pharol do Povo, de 1883; e O Arauto Africano, de 1889. Após a publicação desses títulos de perfil mais político e comercial, outros órgãos predominantemente literários surgiram, como $A$ Ventosa, de 1886; O Serão, também de 1886; e O Foguete, de 1888.

Um dos nomes de destaque desse movimento da imprensa livre é o do português Alfredo Troni, bastante conhecido por sua atuação na literatura angolana nascente. Bacharel em Direito pela Universidade de Coimbra, Troni exerceu importante carreira pública na África, passando por São Tomé, Cabo Verde e Angola, e tendo, segundo documentos da época, "adquirido larga notoriedade pelo brilhantismo da sua inteligência e cultura, pelos seus sentimentos humanitários combatendo a escravatura e defendendo os indígenas" (CHAVES, 1999, p. 36).

Estando em Angola e adotando essa terra como sua, Troni não se manteve calado frente às desigualdades que observava. A imprensa foi um dos caminhos escolhidos por ele para tecer suas críticas às opressões do sistema colonial. Tornou-se um dos maiores jornalistas de sua época e foi o responsável pela criação de três importantes periódicos: Jornal de Loanda, em 1878; Mukuarimi ("Linguarudo", em quimbundo), em 1888; e Conselhos do Leste, em 1891. O primeiro merece destaque por ter marcado "a transição de um jornalismo preferencialmente colonial para um jornalismo cada vez mais apegado às coisas de Angola e do seu povo" (TRIGO, 1977, p. 39). Esse periódico, de forte perfil intervencionista e denunciador, foi responsável por divulgar, na época, artigos de questionamento à administração colonial, ao poder clerical e à violência praticada pela polícia.

Também foi no Jornal de Loanda que apareceu o "primeiro sinal crítico de apoio à criação pelos angolanos de uma literatura em que tivesse expressão a sua especificidade própria, territorial e humana" (OLIVEIRA, 1997, p. 22). Por isso, no Jornal de Loanda constavam crônicas literárias, folhetins e poemas bilíngues que traziam a mistura entre o português e termos e expressões em quimbundo. O veículo também foi um dos principais responsáveis pela divulgação do livro de poemas Espontaneidades da minha alma do angolano Maia Ferreira, que, como já dissemos, havia sido publicado três décadas antes e ficou conhecido por seus conterrâneos a partir das críticas e dos comentários feitos por Troni nas folhas de seu jornal.

Não apenas destaque no movimento da imprensa livre, Troni foi o responsável ainda pela publicação daquela que é considerada a "peça fundadora" (LARANJEIRA, 1995, p. 45) da narrativa angolana: a noveleta Nga Muturi que significa "Senhora Viúva". A obra foi publicada em folhetins em junho e julho de 1882 no Diário da Manhã, de Lisboa, e depois no Jornal das Colônias, de julho a agosto do mesmo ano. Seu texto é marco do início da literatura local porque nos narra as "cenas de Loanda" (subtítulo da obra) não a partir de um olhar redutor ou repleto de preconceitos, mas sim a partir das observações de quem procurou entender a terra estrangeira em que estava, mostrando, em suas diferenças, os dois mundos culturais que lá havia, sem estabelecer as hierarquias tão caras ao discurso colonizador. Como observa Rita Chaves, Nga Muturié uma peça importante na cultura local, pois "constituiu, no domínio da prosa de ficção, a primeira tentativa de apreender o já 
mesclado mundo de hábitos e valores em que se ia construindo o que mais tarde seria conhecido como angolanidade" (CHAVES, 1999, p. 36). Outra figura importante do século XIX em Angola foi Joaquim Dias Cordeiro da Matta, um dos grandes valorizadores da cultura local. Seguindo o exemplo do missionário suíço Héli Chatelain, que também foi colaborador da imprensa de então com artigos publicados n'O Mercantil Cordeiro da Matta convocou seus compatriotas jovens à missão de dedicar algumas horas de ócio ao desenvolvimento de uma literatura própria. Seus artigos estiveram estampados em jornais da época, como O Pharol do Povo, O Arauto Africano e no próprio Jornal de Loanda, fundado e dirigido por Troni. Neste, Cordeiro da Matta possuía uma coluna fixa intitulada "Jeremiadas Históricas", na qual denunciava periodicamente as mazelas e os flagelos por que passavam os moradores de Luanda.

Nesses periódicos também ganharam visibilidade os poemas de Cordeiro da Matta, muitos deles dedicados a criticar a realidade. Um dos principais exemplos dessa conduta é "Libelo a Portugal", de 1883, publicado originalmente n'O Pharol do Povo. O texto trata da contradição entre o presente "moribundo" da pátria portuguesa e seu passado glorioso, cantado por Camões e por Alexandre Herculano, defendendo, no fim, a liberdade de sua pátria:

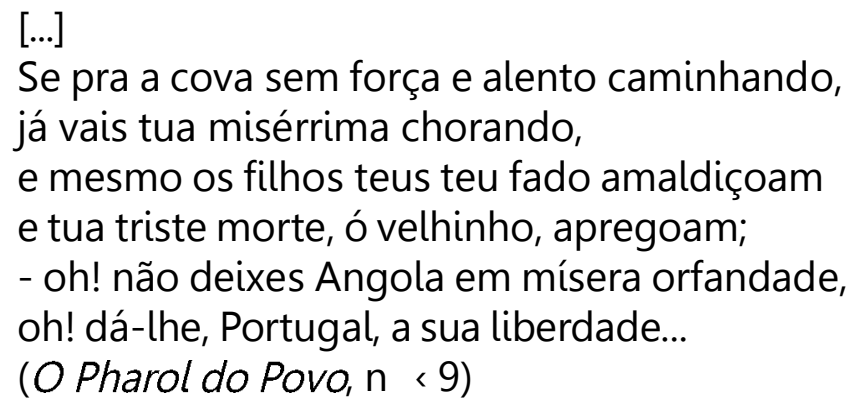

Em 1890, mais de cem poemas seus foram reunidos no conjunto Delírios, o qual, para Rita Chaves, "reforça a ruptura em relação à lírica tradicional portuguesa uma vez que escolhe tematizar a questão racial, até então intocada pela poesia angolana" (CHAVES, 1999, p. 37). "Negra!" e "Kicôla!", dois de seus poemas mais conhecidos, são mostras dessa ruptura, pois é à mulher negra africana que os versos se dirigem, contemplando-a em sua beleza. O segundo já inscreve o quimbundo no corpo do poema desde o título, e significa não, pode ser! - o que só descobrimos em um dos versos finais, quando sentimos a força da negação direcionada não apenas às investidas do sujeito lírico, mas também, e principalmente, a toda imposição colonial; não este que, proferido por uma africana, faz coro a todo o nãoque vinha sendo gritado pela imprensa livre. Esse texto, "Kicôla!", dialoga com a "Poesia" de João da Cruz Toulson que havia sido publicada no Jornal de Loanda em 1878, a quem inclusive da Matta faz referência na abertura de seus versos. Em atitude semelhante, no texto de Toulson também a bela menina nega as investidas do eu-lírico em língua banta, dizendo-lhe Canã'ngána, o que quer dizer "não senhor".

Uma publicação que colaborou muito para a divulgação dos poemas produzidos por angolanos na segunda metade do século XIX foi o Almanach de Lembranças, no qual foram publicados os dois poemas de 
Cordeiro da Matta acima citados. Editada fora de Angola e dirigida pelos poetas portugueses Alexandre Magno de Castilho e Antônio Xavier Rodrigues, "nenhuma publicação não-oficial, durante tão largo período, ao longo da segunda metade do século XIX, manteve permanente presença de artigos de interesse e origem angolanos" (OLIVEIRA, 1997, p. 26).

Os laços firmados entre o jornalismo e a literatura angolana na origem de ambos foram tão fortes que acabaram atravessando décadas e serviram de inspiração e tema para algumas obras ficcionais no século seguinte. Em 1929, quando Antonio de Assis Júnior publica, em folhetins no jornal $A$ Vanguarda, o romance $O$ Segredo da Morta, ele recupera em sua ficção o momento em que veio a público a obra coletiva Voz de Angola Clamando no Deserto, lançada em 1901 sob a responsabilidade de onze jornalistas da imprensa livre. A publicação havia sido definida por seus organizadores como uma reação a um artigo racista divulgado meses antes pela Gazeta de Loandachamado "Contra Lei pela Grey", que dizia, por exemplo, que o negro não era um homem. O conjunto se propunha a combater não apenas as calúnias reproduzidas pelo artigo em questão, mas também - e principalmente - os modos de significar o continente africano, pois, como nos ensina Said, o imperialismo "havia monopolizado o sistema inteiro de representações" (SAID, 1995, p. 57), e era preciso fazer frente a esse sistema. Um dos principais questionamentos presentes nos textos era a discrepância entre o argumento salvatório, que justificava a expansão, e as práticas de exploração.

A obra de Assis Júnior tem seu enredo situado exatamente nos anos 1899 e 1900, apresentando aos leitores uma mulher, portanto duplo da terra, que, apesar de seu corpo "morto", retorna, vinga-se e (re)escreve a sua história. O romance recupera o clima da passagem do século XIX ao $X X$, quando, assim como a personagem Ximinha Belchior, também Angola mostrou que não estava morta e que, apesar da exploração devastadora, era necessário e possível que o país reagisse. O lançamento de jornais contestadores e o conjunto Voz de Angola são alguns exemplos dessa resistência, transformados em literatura no momento em que se implantou o Estado Novo em Portugal, na década de 1920, trazendo com ele o silenciamento das ideias opositoras e o estímulo de uma produção simbólica que justificasse a colonização. É por isso que $O$ Segredo da Mortaé uma obra tão importante, considerada uma exceção no momento em que as vozes de Angola foram proibidas e deixaram de clamar.

Setenta anos se passaram desde o romance de Assis Júnior e a importância da geração da imprensa livre do século XIX não ficaria esquecida, retornando à ficção angolana com a publicação, em 1999, do romance $A$ Casa Velha das Margens, escrito pelo angolano Arnaldo Santos. A obra, que se passa gpor volta de 1889 h (SANTOS, p. 9, 1999), traz à cena literária alguns dos principais periódicos e alguns dos nomes de destaque daquele momento, como o de Joaquim Cordeiro da Matta, "poeta de provas provadas no 'Almanach de Lembranças' e renomado em livro" (, 1999, p. 10) e o de José de Fontes Pereira, um dos homens mais inflamados contra a política colonial, "jornalista do ciclo de amizades de Cordeiro da Matta" (SANTOS, 1999, p. 28). Urbano Monteiro de Castro, João da Ressurreição Arantes Braga, Cornélio Castro Francina, Pedro Félix Machado, Inocêncio Mattoso da Câmara, Arsénio de Carpo e outros 
intelectuais são convocados para compor a constelação de personagens históricos presentes no texto. Esses, juntamente com Cordeiro da Matta e Fontes Pereira, são alguns dos nomes mais representativos do jornalismo combativo e nacionalista do final do século XIX, pois fundaram e colaboraram com muitos dos periódicos que se produziam então.

Com a obra de Arnaldo Santos é possível perceber o clima de descontentamento predominante naquele momento, o que incentivou os naturais de Angola a se reunirem em clubes, grêmios e associações, e a lançarem jornais que divulgassem suas angústias. Como já sabemos, aquele ainda não seria o momento da mudança, como reconhece Emídio Mendonça, personagem em torno do qual a trama se constrói: "Um caminho longo ainda haveria que ser palmilhado para que os filhos do país fossem 'senhores naturais das suas terras', os muêne'xi [...]" (1999, p. 289). De fato um longo caminho precisou ser trilhado até que jovens se reunissem no Movimento dos Novos Intelectuais e lançassem, em 1948, seu grito de "Vamos descobrir Angola!". Mas as sementes desse movimento estão ali, no século XIX, quando os velhos intelectuais se reuniram em torno de um jornalismo que, começando a se constituir, serviu para estimular uma literatura que, aos poucos, foi se (a)firmando como voz em diferença.

\section{REFERÊNCIAS BIBLIOGRÁFICAS}

CHAVES, Rita. A Formação do Romance Angolano - Entre Intenções e Gestos. São Paulo: Coleção Via Atlântica, 1999.

LARANJEIRA, Pires. Literaturas africanas de expressão portuguesa. Lisboa: Universidade Aberta, 1995.

OLIVEIRA, Mário António Fernandes de Oliveira. A Formação da Literatura Angolana (1851-1950). Lisboa: Imprensa Nacional Casa da Moeda, 1997.

SAID, Edward. Cultura e Imperialismo. Trad. Denise Bottman. São Paulo: Companhia das Letras, 1995.

SANTOS, Arnaldo. A Casa Velha das Margens. Porto: Campo das Letras, 1999.

TRIGO, Salvato. Introdução à Literatura Angolana de Expressão Portuguesa. Porto: Brasília Editora, 1977.

TRONI, Alfredo. Nga Muturi-Cenas de Loanda. Lisboa: Ed. 70, 1973.

VV.AA. Voz de Angola Clamando no Deserto. Lisboa: Ed. 70, 1984. 